CONCISE REPORT

\title{
Small vessel vasculitis and relapsing panniculitis in tumour necrosis factor receptor associated periodic syndrome (TRAPS)
}

\author{
P Lamprecht, F Moosig, S Adam-Klages, U Mrowietz, E Csernok, M Kirrstetter, K Ahmadi-Simab, \\ J O Schroder, W L Gross
}

Case reports: A 66 year old female patient had relapsing fever and non-suppurative panniculitis suggestive of enigmatic "Weber-Christian disease" (WCD). Antineutrophil cytoplasmic antibodies with specificity for human leucocyte elastase (HLE-ANCA) were detected. A biopsy showed small vessel vasculitis and panniculitis. A 53 year old man had recurrent episodes of abdominal pain, erythematous rash, and myalgia. Fever attacks had stopped a few years ago. A biopsy showed panniculitis and fasciitis. In both patients mutations (R92Q, T50M) of the tumour necrosis factor receptor super family (TNFRSF) 1A gene were disclosed. Mutations of the TNFRSF 1A gene are the cause of tumour necrosis factor receptor associated periodic syndrome (TRAPS). Both patients responded favourably to treatment with the human soluble $\mathrm{p} 75 \mathrm{TNF} \alpha$ receptor fusion protein etanercept ( $2 \times 25 \mathrm{mg}$ subcutaneously/week).

Discussion: Small vessel vasculitis and panniculitis have not been reported in TRAPS so far. The cases underline the importance of TNF $\alpha$ regulation in inflammatory processes including vasculitis. Genetically determined causes of fever may account for some cases of WCD.

$\mathrm{R}$ elapsing febrile panniculitis ("Weber-Christian disease" (WCD) ) is an enigmatic clinical problem. It may present as idiopathic disease or in a variety of other conditions, such as connective tissue diseases or lymphomas. However, many authors doubt that WCD is a separate disease entity. ${ }^{1}$ Cutaneous manifestations have also been reported in hereditary periodic fever syndromes such as familial Mediterranean fever (FMF), hyperimmunoglobulinaemia D and periodic fever syndrome, and tumour necrosis factor receptor associated periodic syndrome (TRAPS). ${ }^{2}$ Herein, we report on two patients apparently with WCD in whom a genetically determined cause of their vasculitis (patient 1) and panniculitis and fever (both patients) was disclosed.

\section{CASE REPORTS}

\section{Case 1}

A 66 year old white woman had had relapsing episodes of fever, migratory erythematous macules, oligoarthritis, and myalgias for years, but not in her childhood. The erythrocyte sedimentation rate, $\mathrm{C}$ reactive protein, and leucocyte counts rose dramatically during her recurrent attacks of fever, oligoarthritis, and macules. A skin biopsy showed a small vessel vasculitis and panniculitis (fig 1). Antineutrophil cytoplasmic antibodies with specificity for human leucocyte elastase (HLE-ANCA) were repeatedly detected, but no other symptoms of systemic vasculitis were found. Infectious

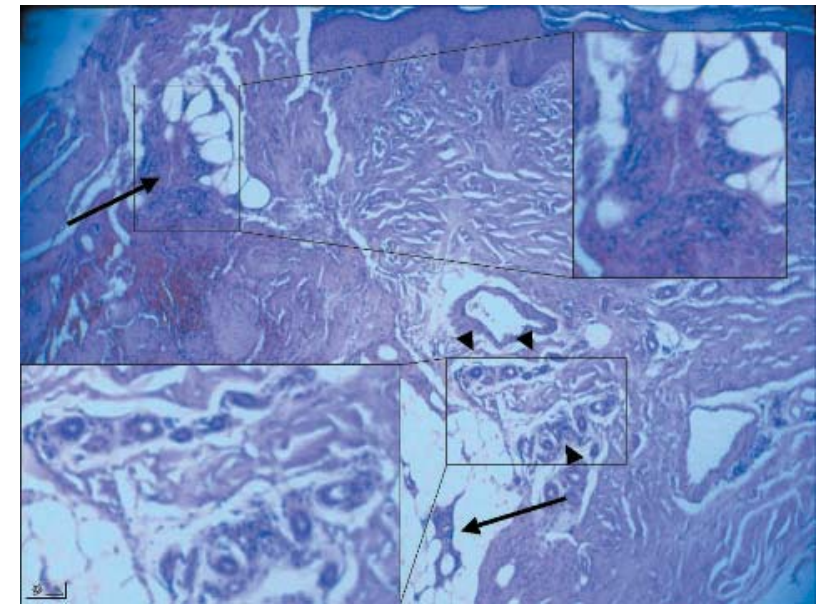

Figure 1 Skin biopsy demonstrating panniculitis (arrows) and small vessel vasculitis (arrow heads) in our patient. The insertions show magnifications of the marked areas.

diseases, haematological neoplasia and solid tumours, $\alpha_{1}$ antitrypsin deficiency, pancreatic diseases, and primary or secondary systemic vasculitides were excluded. The clinical presentation seemed to be consistent with the diagnosis of an idiopathic WCD. The patient had not responded sufficiently to various immunosuppressive treatments (colchicine, gold, methotrexate, leflunomide, azathioprine). Therefore, genetically determined causes of recurrent fever were also evaluated. FMF was excluded by MEFV gene analysis. Serum IgD levels were repeatedly normal. Analysis of the tumour necrosis factor receptor super family (TNFRSF) IA gene was performed as described previously, ${ }^{3}$ demonstrating the R92Q mutation (fig 2). TRAPS was diagnosed. The patient reported that two sisters living in Russia had similar symptoms. The patient responded favourably to treatment with the human soluble p75 tumour necrosis factor $\alpha(\mathrm{TNF} \alpha)$ receptor fusion protein etanercept $(2 \times 25 \mathrm{mg}$ subcutaneously/ week).

\section{Case 2}

A 53 year old white man had recurrent episodes of abdominal pain, erythematous skin rash, and myalgia accompanied by increased serological markers of inflammation. Symptoms

Abbreviations: FMF, familial Mediterranean fever; HLE-ANCA, antineutrophil cytoplasmic antibodies with specificity for human leucocyte elastase; PCR, polymerase chain reaction; TNF $\alpha$, tumour necrosis factor $\alpha$; TNFRSF, tumour necrosis factor receptor super family; TRAPS, tumour necrosis factor receptor associated periodic syndrome; WCD, "Weber-Christian disease" 
A B

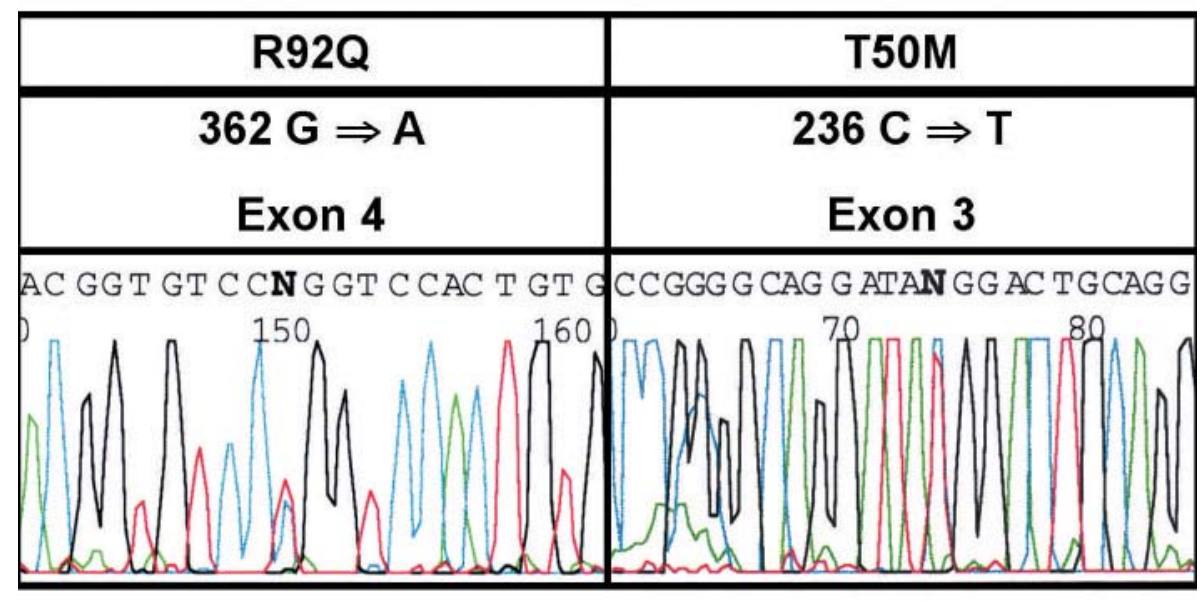

Figure 2 DNA sequence electropherogram demonstrating the TNFRSF 1A gene mutation. Single nucleotide substitutions (missense mutations) in different exons result in the substitution of single amino acids in the transcribed p55 TNF receptor. Polymerase chain reaction (PCR) of exons $2-5$ of the TNFRSF 1A gene was performed twice using primers as described previously. ${ }^{3}$ PCR products were purified and sequenced in both directions demonstrating the $R 92 Q$ mutation in patient 1 and the T50M mutation in patient 2.

including fever had occurred early in childhood, but he had not had fever for many years. ANCA were not detected. Renal and other functions were normal. A biopsy disclosed panniculitis and fasciitis. In contrast with the first patient, no small vessel vasculitis was seen in the biopsies. Again the clinical presentation seemed consistent with the diagnosis of WCD. Symptoms responded to high dose prednisolone (>50 mg/day), but recurred upon tapering of the dose. Family history was remarkable for his late father who had had abdominal pain and arthralgia. Two of his children had recurrent febrile episodes. Analysis of the TNFRSF IA gene disclosed the T50M mutation in the patient (fig 2) and both children (data not shown). TRAPS was diagnosed. Etanercept treatment $(2 \times 25 \mathrm{mg}$ subcutaneously/week $)$ resulted in remission of the disease and successful tapering of the dose of concomitant prednisolone.

\section{DISCUSSION}

We found mutations (R92Q, T50M) in the TNFRSF 1A gene coding for the p55 TNF receptor as the underlying cause of recurrent febrile episodes and biopsy proven panniculitis in two patients. One patient also had cutaneous small vessel vasculitis. The other had fasciitis. Both patients had systemic manifestations such as oligoarthritis, migratory erythematous macules, oligoarthritis, and myalgia. To our knowledge small vessel vasculitis and panniculitis have not been reported in TRAPS so far.

TRAPS is caused by mutations in the extracellular region of the $\mathrm{p} 55 \mathrm{TNF} \alpha$ receptor, resulting in impaired cleavage and down regulation of the membrane expressed form of the receptor, a diminished shedding of the potentially antagonistic soluble form of the receptor, and-as a consequenceunbalanced TNF $\alpha$ action. ${ }^{3}{ }^{4}$ Miscellaneous clinical manifestations such as migratory erythematous macules, fasciitis, arthralgia, myalgia, abdominal and pleuritic chest pain have been reported in TRAPS. ${ }^{5-7}$ Our first patient also had migratory erythematous macules, but unlike the second patient no erythematous nodules typical of panniculitis. Low titre HLE-ANCA were repeatedly detected in our first patient, but the relation to TRAPS (as well as to other vasculitides) remains unclear. Interestingly, ANCA have been shown before in another hereditary disorder characterised by low major histocompatibility complex class I expression, a dysregulated immune response, and a clinical condition closely resembling Wegener's granulomatosis. ${ }^{8}$ The second patient had fasciitis and panniculitis. Fasciitis has been reported as a manifestation of TRAPS only recently. ${ }^{7}$

Based on our findings and previous reports on dermatological and systemic manifestations, ${ }^{3-7}$ it seems likely that impaired TNF $\alpha$ regulation might predominantly affect the skin as well as the synovia and mesothelia-that is, highly vascularised tissues, in TRAPS. Premature leucocyte activation due to impaired $\mathrm{TNF} \alpha$ regulation and consecutive endothelial damage might result in vasculitis or panniculitis, or both, in some patients with TRAPS. The observation of vasculitis in TRAPS also adds further weight to reports on a pivotal role of impaired TNF $\alpha$ regulation in the pathogenesis of some primary systemic vasculitides such as Wegener's granulomatosis. ${ }^{9}$ Against this background TNF $\alpha$ blockade with the human soluble p75 TNF $\alpha$ receptor fusion protein etanercept is advocated as the preferred treatment in TRAPS. ${ }^{10} 11$

Of note, we analysed another three patients presenting with relapsing febrile non-suppurative panniculitis of unknown cause for mutations of the TNFRSF 1A gene and other causes of hereditary periodic fevers. We found no mutations in these three patients. Our report suggests that other currently unknown hereditary and environmental factors might still be disclosed as causes of "idiopathic" relapsing panniculitis and vasculitides.

\section{Authors' affiliations}

P Lamprecht, E Csernok, M Kirrstetter, K Ahmadi-Simab, W L Gross, Department of Rheumatology, University Hospital of Schleswig-Holstein, Campus Luebeck, and Rheumaklinik Bad Bramstedt, Luebeck, Germany F Moosig, J O Schroder, Second Medical Department, University Hospital of Schleswig-Holstein, Campus Kiel, Kiel, Germany

S Adam-Klages, Institute of Immunology, University Hospital of Schleswig-Holstein, Campus Kiel, Kiel, Germany

U Mrowietz, Department of Dermatology, University Hospital of Schleswig-Holstein, Campus Kiel, Kiel, Germany

Correspondence to: Dr P Lamprecht, Department of Rheumatology, University Hospital of Schleswig-Holstein, Campus Luebeck, and Rheumaklinik Bad Bramstedt, Ratzeburger Allee 160, 23538 Luebeck, Germany; lamprecht@rheuma-zentrum.de

Accepted 27 January 2004 


\section{REFERENCES}

1 White JW Jr, Winkelmann RK. Weber-Christian panniculitis: a review of 30 cases with this diagnosis. J Am Acad Dermatol 1998;39:56-62.

2 Drenth JPH, van der Meer JWM. Hereditary periodic fever. N Engl J Med 2001;345:1748-57.

3 McDermott MF, Aksentijevich I, Galon J, Ogunkolade BW, Centola M, Mansfield $\mathrm{E}$, et al. Germline mutations in the extracellular domains of the $55 \mathrm{kDa}$ TNF receptor, TNFR1, define a family of dominantly inherited autoinflammatory syndromes. Cell 1999:97:133-44.

4 Galon J, Aksentijevich I, McDermott MF, O'Shea JO, Kastner DL. TNFRSFIA mutations and autoinflammatory syndromes. Curr Opin Immunol 2000; 12:479-86

5 Toro JR, Aksentijevich I, Hull K, Dean J, Kastner DL. Tumor necrosis factor receptor-associated periodic syndrome: a novel syndrome with cutaneous manifestations. Arch Dermatol 2000;136:1487-94.

6 Dode C, Andre M, Bienvenu T, Hausfater P, Pecheux C, Bienvenu J, et al. The enlarging clinical, genetic, and population spectrum of tumor necrosis factor receptor-associated periodic syndrome. Arthritis Rheum 2002;46:2181-8.

7 Hull KM, Wong K, Wood GM, Chu WS, Kastner DL. Monocytic fasciitis: a newly recognized clinical feature of tumor necrosis factor receptor dysfunction. Arthritis Rheum 2002;46:2189-94.

8 Moins-Teisserenc HT, Gadola SD, Cella M, Dunbar PR, Exley A, Blake N et al. Association of a syndrome resembling Wegener's granulomatosis with low surface expression of HLA class-I molecules. Lancet 1999;354:1598-603.

9 Komocsi A Lamprecht P, Csernok E, Muller A, Holl-Ulrich K, Seitzer U, et al. Peripheral blood and granuloma CD $4^{+} \mathrm{CD} 28^{-}$T-cells are a major source of IFN- $\gamma$ and TNF- $\alpha$ in Wegener's granulomatosis. Am J Pathol 2002;160:1717-24

10 Drewe E, McDermott EM, Powell RJ. Treatment of the nephrotic syndrome with etanercept in patients with the fumor necrosis factor receptor-associated periodic syndrome. N Engl J Med 2000;343:1044-5.

11 Simon A, van Deuren M, Tighe PJ, van der Meer JW, Drenth JP. Genetic analysis as a valuable key to diagnosis and treatment of periodic fever. Arch Intern Med 2001;161:2491-3. 